Journal of Animal and Veterinary Advances 11 (16): 3027-3030, 2012

ISSN: $1680-5593$

(C) Medwell Journals, 2012

\title{
The Expression Analysis of Ghrelin and Growth Hormone Secretagogue Receptor in Mouse Thymic Epithelial Cells
}

\author{
Jian-Hong Liu, Yong-Jiang Ma, Ying Li, Hai-Bin Peng, Dao-Tong Li, \\ Yuan Zhan and Yu-Gu Li \\ Laboratory of Anatomy and Histology, College of Veterinary Medicine, \\ South China Agricultural University, 510642 Guang zhou, \\ Guangdong Province, People's Republic of China
}

\begin{abstract}
The present study was to identified the expression of Ghrelin and GHS-R in mouse Medullary-Type Epithelial Cells (MTEC1). Whether the gene of ghrelin and GHS-R are expressing in MTECl cells or not was measured by using Quantitative real time RT-PCR (Q-PCR). Results identified that the mRNA of ghrelin and GHS-R can be detected in MTECl cells. The protein levels of GHS-R and ghrelin precursor were detected by the method of Western blot analysis. Moreover, the location of GHS-R in MTECl cells were detected by immunofluorescence and the quantity of ghrelin in the supernatant of MTEC1 cells were measured by ELISA. The results of Western blot analysis make sure that GHS-R and precursor of ghrelin are expressing in MTEC1 cells. GHS-R is a kind of transmembranes protein. As the results of immunofluorescence shown the quantity of ghrelin in the supernatant of MTECl cells measured by ELISA was $39.20 \mathrm{pg} \mathrm{mL}^{-1}$ while the control was $5.74 \mathrm{pg} \mathrm{mL}^{-1}$.
\end{abstract}

Key words: Ghrelin, GHS-R, MTECl cells, expression, prokin, China

\section{INTRODUCTION}

Ghrelin is a peptide hormone and is firstly found in the rat stomach in 1999. The Open Reading Frame (ORF) of mouse ghrelin mRNA is $354 \mathrm{bp}$ and the deduced protein contained 117 amino acid (aa) which is the precursor of ghrelin (Kojima et al., 1999). After translation, precursor of Ghrelin was spliced and mature Ghrelin is a 28 aa peptide. Ghrelin is mainly produced by the stomach whereas substantially lower amounts are derived from the bowel, pituitary, kidney and placenta (Date et al., 2000; Hosoda et al., 2000; Ariyasu et al., 2001; Korbonits et al., 2001). The earlier studies have demonstrated that ghrelin plays a key role in response to negative energy balance and promotes Growth Hormone (GH) secretion from the pituitary via binding to its 7-Transmembranes G Protein-Coupled Receptor (7-TM GPCR), the GH Secretagogue Receptor (GHS-R) (Kojima et al., 1999; Smith, 2005).

The GHS-R of human and swine including two distinctive cDNAs which are GHS-R type la and GHS-R type 1b (Howard et al., 1996). GHS-R type la encodes a 7-TM GPCR with binding and functional properties consistent with its role as ghrelin's receptor while GHS-R type $1 \mathrm{~b}$ encodes a 5-TM GPCR with no measurable function (Howard et al., 1996). There is no reports identified the GHS-R of mouse can be divide into any subtype until now on. The mRNA of GHS-R can be detected through RT-PCR in many peripheral organs including heart, lung, liver, kidney, pancreas, stomach, small and large intestines, adipose tissue and immune cells (Guan et al., 1997; Hattori et al., 2001; Gnanapavan et al., 2002) which indicates that ghrelin may have multiple functions in these tissues.

Ghrelin has the ability to promote thymopoiesis during aging (Dixit et al., 2007). In the thymus, thymocyte development is dependent upon the sequential contribution of morphologically and phenotypically distinct stromal cell compartments that comprise the thymic microenvironment (Anderson et al., 2000; Anderson and Jenkinson, 2001; Kyewski et al., 2002). The thymic epithelial cells are a major component of the stromal cells of the thymus and provide a crucial signal for intrathymic $\mathrm{T}$ cell development and selection (Rouse et al., 1988; Ritter and Palmer, 1999). The earlier studies have demonstrated that ghrelin and its receptor played a key role in the regulation of thymic restore (Dixit et al., 2007).

In order to research the mechanism of the role of ghrelin and its receptor in regulation of thymic development, researchers measured the expression levels of ghrelin and GHS-R in cultured MTEC1 cells.

Corresponding Author: Yu-Gu Li, Laboratory of Anatomy and Histology, College of Veterinary Medicine, South China Agricultural University, 510642 Guangzhou, Guangdong Province, People's Republic of China 


\section{MATERIALS AND METHODS}

Cell culture: MTECl, a mouse (Mus musculus) thymic medullary-type epithelial cell line supporting the unctional maturation of CD4 single-positive thymocytes in vitro (Ge and Chen, 2000) was kindly provided by Dr. Yu Zhang (Department of Immunology, Peking University Health Science Center). These cells were cultured in Dulbecco's Modified Eagle's Medium (Gibco) containing 10\% fetal bovine serum (Fbs; Gibco).

Primers and antibody: To investigate the expression level of ghrelin and Growth Hormone Secretagogue Receptor (GHS-R), the primers, GHS-R-F, GHS-R-R Ghrelin-F and Ghrelin-R were designed and synthesized based on the nucleotide sequences of GHS-R (NM_177330) and ghrelin (NM_021488)(TaKaRa Biotechnology (Dalian China) Co., Ltd.). The primers used in Q-PCR are shown in Table 1. The primary antibody, of GHS-R (sc-10359) used in Western blot and immunofluorescence was obtained from Santa Cruz Biotechnology (Santa Cruz Biotechnology, Inc. California USA). The antibody for Western blot analysis of Ghrelin was purchased from Phoenix Pharmaceuticals, Inc. USA.

Quantitative real time RT-PCR (Q-PCR) assays: MTEC1 cells $\left(1.0 \times 10^{6}\right)$ were harvested at the indicated time points and washed twice with ice-cold PBS. Then, the total RNA $(1 \mu \mathrm{g})$ was isolated with the TRIZOL reagent (Invitrogen). Reaction mixture ( $20 \mathrm{~mL}$ ) containing $1 \mu \mathrm{g}$ of total RNA was reverse transcribed to cDNA using PrimeScript RT-polymerase (Takara). Q-PCR was performed on the cDNA using primers specific for GHS-R and ghrelin, specifically. RNA input was normalized to the level of GAPDH for genes analysis. All reaction were carried out using SYBR Green Mix (Takara) and the PCR conditions for Q-PCR were as follows: activation of enzyme at $94^{\circ} \mathrm{C}$ for $1 \mathrm{~min}, 40$ cycles of denaturation at $94^{\circ} \mathrm{C}$ for $5 \mathrm{sec}$, annealing at $60^{\circ} \mathrm{C}$ for $30 \mathrm{sec}$ and extension at $72^{\circ} \mathrm{C}$ for $30 \mathrm{sec}$. Q-PCR was carried out using a ABI PRISM ${ }^{\circledast}$ every cycle. The fluorescence of samples was continuously traced during this period. Relative expression levels were calculated as ratios normalized against those of GAPDH. These experiments were repeated three times. All results are expressed as the means $\pm \mathrm{SD}$ of three independent experiments.

ELISA assays: The supernatant of MTECl cells is prepared ELISA was carried out according to the manufacturer's instruction (Uscn Life Science, USA. E90991Mu). Finally, measurement was conduct at $450 \mathrm{~nm}$ immediately. The control group was culture medium.

Western blot analysis: MTECl cells $\left(3.0 \times 10^{6}\right)$ were harvested, washed twice with ice-cold PBS and lysed in $0.5 \mathrm{~mL}$ of lysis buffer. Equal amounts (60 mg) of proteins were loaded and resolved by Sodium Dodecylsulfate polyacrylamide Gel Electrophoresis (SDS-PAGE) and then transferred onto immobilon membrane (Millipore). The membrane was blocked with $5 \%$ non-fat milk in Tris-Buffered Saline (TBS, $\mathrm{pH}$ 7.4) for $1 \mathrm{~h}$ and then incubated with antibodies (GHS-R: 1:1000, Ghrelin: 1:500) in $5 \%$ non-fat milk in TBS. After the incubation of primary antibody, the membrane was washed with TBS including 5\% Tween-20 (TBST) and incubated with secondary antibodies conjugated with horseradish peroxidase in 5\% non-fat milk in TBS. After washing with TBST, the bound antibodies were visualized by immobilon Western chemilluminescent HRP substrate (Millipore) and recorded on X-ray films.

Immunofluorescence: $\mathrm{MTECl}$ cells were grown on cover glasses in six-well plates and were fixed with $4 \%$ formaldehyde for $30 \mathrm{~min}$, permeabilized with $0.2 \%$ Triton $\mathrm{X}-100$ for $5 \mathrm{~min}$. Then cells blocked with 3\% BSA at $37^{\circ} \mathrm{C}$ for $2 \mathrm{~h}$. Following, primary antibody for GHS-R (Phoenix Pharmaceuticals, Inc. USA) was deliquation according directions and incubated cells at $4{ }^{\circ} \mathrm{C}$ overnight. The secondary antibody (1:2,000, Alexa 594-conjugated anti-mouse IgG) applied for $1 \mathrm{~h}$ at room temperature. And the cells was incubated in 0.1-1 $\mathrm{mg} \mathrm{mL}^{-1}$ DAPI (DNA stain) for $1 \mathrm{~min}$. Triple washing with PBS was performed between each step. Finally, the coverslips were mounted in PPD-mounting medium ( $90 \%$ glycerol). Images were taken using Fluorescence microscope (Leica., Germany).

Table 1: The primers used in this study

\begin{tabular}{lll}
\hline Abbreviation & Primer sequence $\left(5^{\prime}-3^{\prime}\right)$ & Description \\
\hline GHS-R-F & ATCACCTCTGGGTCTTGTTGCTG & Quantitative RT-PCR primer, forward \\
GHS-R-R & GCTGAATGGCTCATTGTAGTCCTG & Quantitative RT-PCR primer, reverse \\
Ghrelin-F & TTGGCATCAAGCTGTCAGGAG & Quantitative RT-PCR primer, forward \\
Ghrelin-R & GTCATGGCCTGTCCGTGGTTA & Quantitative RT-PCR primer, reverse \\
Gapdh-F & GTGTCCGTCGTGGATCTGA & Quantitative RT-PCR primer, forward \\
Gapdh-R & TTGCTGTTGAAGTCGCAGGAG & Quantitative RT-PCR primer, reverse \\
\hline
\end{tabular}




\section{RESULTS AND DISCUSSION}

mRNA expression level: Q-PCR was carried out as described in material and method. As shown in Fig. 1, the mRNA of the ghrelin and GHS-R were both detected in MTECl cells. The average threshold cycle of ghrelin mRNA is 25.06 and the average threshold cycle of GHS-R mRNA is 25.18. Comparatively, the control gene, GAPDH whose average threshold cycle is 14.46 was also been tested.

Protein expression profile: To investigate the expression of ghrelin and its precursor in MTECl cells in vitro, researchers make use of ELISA to detect the quantity of ghrelin and Western blot was performed to detect the precursor of ghrelin. ELISA was carried out according to the manufacturer's instruction. The concentration of ghrelin in the supernatant of MTECl cells is $39.20 \mathrm{pg} \mathrm{mL}^{-1}$ while the control is $5.74 \mathrm{pg} \mathrm{mL}^{-1}$ according to the standard curve shown in Fig. 2. And the protein of ghrelin precursor was also been detected in MTECl cells (Fig. 3).

In this study, Western blot and immunofluorescence was used to detect the expression of GHS-R. The result

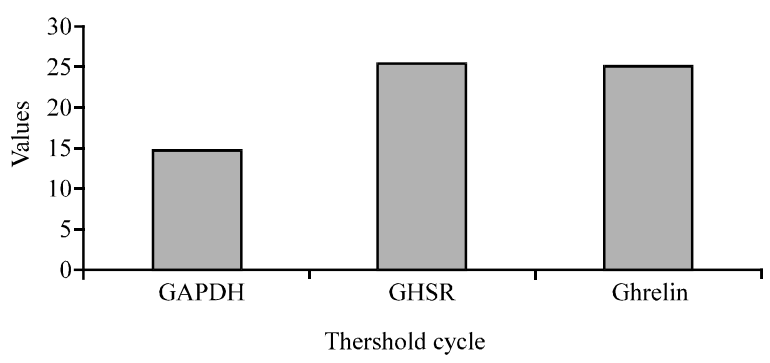

Fig. 1: Ghrelin and GHS-R expression levels in mouse MTEC1 cells were detected by Q-PCR analysis. GAPDH serves as internal control. The bars indicate mean $\pm \mathrm{SD}$ from three different experiments

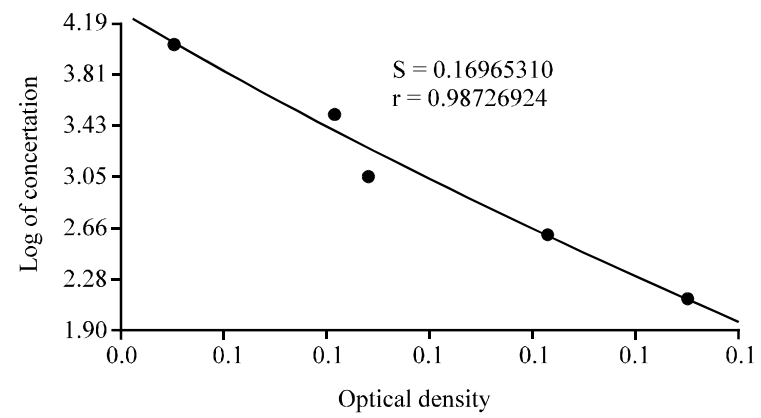

Fig. 2: Typical standard curve for mouse ghrelin ELISA analysis indicated that the expression of GHS-R can be measured in MTECl cells and it is a kind of transmembranes protein as shown in Fig. 3. In addition, the expression of GHS-R was detected by Western blot analysis as it's shown in Fig. 4.

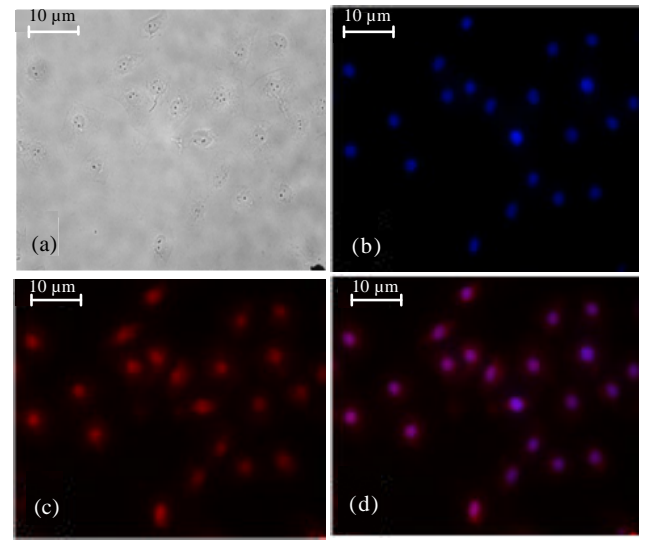

Fig. 3: Immunofluorescence analyses of expression levels of GHS-R in mouse MTECl cells. a) photos of MTEC1 taken on natural light; b) the nuclei stained blue fluorescence; c) GHS-R stained red fluorescence and d) merge the nuclei and GHS-R

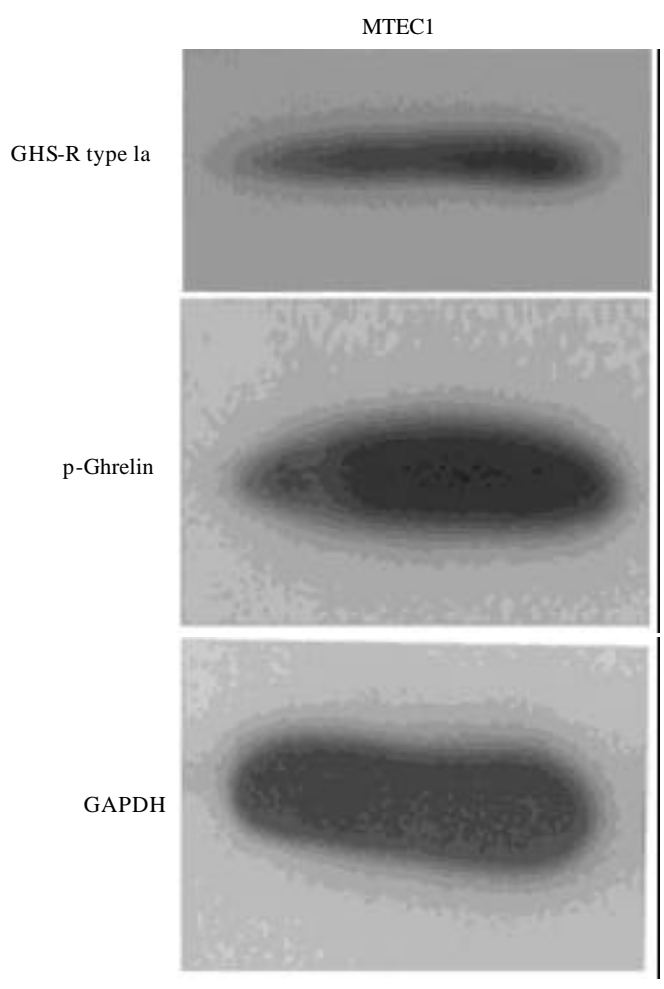

Fig. 4: Western blot analysis of GHS-R and precursor Ghrelin (p-Ghrelin) in mouse MTECl cells 
The thymus is critical for the development, selection and maintenance of the peripheral $\mathrm{T}$ cell pool possessing a broad spectrum of TCR specificities (Dixit et al., 2007). Moreover, thymic epithelial cells provide a crucial signal for intrathymic $\mathrm{T}$ cell development and selection. And ghrelin has been reported to have the function of activating human $\mathrm{T}$ cells and mediating anti-inflammatory signals in several cells types.

\section{CONCLUSION}

By this study, researchers firstly investigated the expression of ghrelin and GHS-R in the MTECl cells in vitro. The results indicated that the mRNA and protein of Ghrelin and GHS-R can both be detected in the MTEC1 cells. Based on the results of present study, researchers can investigate the role of ghrelin and GHS-R in the MTEC1 in further based on this model.

\section{ACKNOWLEDGEMENTS}

This research was financially supported in part by the National Natural Science Foundation of China (No.: 30871834) and Research Fund for the Doctoral Program of Higher Education of China (No.: 20094404110015). Researchers also want to express the gratitude to Dr. Yu Zhang (Department of Immunology, Peking University Health Science Center) for kindly providing of MTEC1 cells.

\section{REFERENCES}

Anderson, G. and E.J. Jenkinson, 2001. Lymphostromal interactions in thymic development and function. Nat. Rev. Immunol., 1: 31-40.

Anderson, G., B.C. Harman, K.J. Hare and E.J. Jenkison, 2000. Microenvironmental regulation of cell development in the thymus. Semin Immunol., 12: $457-464$.

Ariyasu, H., K. Takaya, T. Tagami, Y. Ogawa, K. Hosoda and T. Akamizu, 2001. Stomach is a major source of circulating ghrelin, and feeding state determines plasma ghrelin-like immunoreactivity levels in humans. J. Clin. Endocrinol. Metab., 86: 4753-4758.

Date, Y., M. Kojima, H. Hosoda, A. Sawaguchi and M.S. Mondal et al., 2000. Ghrelin, a novel growth hormone-releasing acylated peptide, is synthesized in a distinct endocrine cell type in the gastrointestinal tracts of rats and humans. Endocrinology, 141: 4255-4261.

Dixit, V.D., H. Yang, Y. Sun, A.T. Weeraratna, Y.H. Youm, R.G. Smith and D.D. Taub, 2007. Ghrelin promotes thymopoiesis during aging. J. Clin. Invest., 117: 2778-2790.
Ge, Q. and W.F. Chen, 2000. Effect of murine thymic epithelial cell line (MTEC1) on the functional expression of $\mathrm{CD} 4(\mathrm{R}) \mathrm{CD} 8(-)$ thymocyte subgroups. Int. Immunol., 12: 1127-1133.

Gnanapavan, S., B. Kola, S.A. Bustin, D.G. Morris and P. McGee et al., 2002. The tissue distribution of the mRN A of ghrelin and subtypes of its receptor, GHS-R, in humans. J. Clin. Endocrinol. Metab., 87: 2988-2991.

Guan, X.M., H. Yu, O.C. Palyha, K.K. McKee, S.D. Feighner and D.J. Sirinathsinghji, 1997. Distribution of mRNA encoding the growth hormone secretagogue receptor in brain and peripheral tissues. Brain Res. Mol. Brain Res., 48: 23-29.

Hattori, N., T. Saito, T. Yagyu, B.H. Jiang, K. Kitagawa and C. Inagaki, 2001. GH, GH receptor, GH secretagogue receptor and ghrelin expression in human T cells, B cells and neutrophils. J. Clin. Endocrinol. Metab., 86: 4284-4291.

Hosoda, H., M. Kojima, H. Matsuo and K. Kangawa, 2000. Ghrelin and des-acyl ghrelin: Two major forms of rat ghrelin peptide in gastrointestinal tissue. Biochem. Biophys. Res. Commun., 279: 909-913.

Howard, A.D., S.D. Feighner, D.F. Cully, J.P. Arena and P.A. Liberator et al., 1996. A receptor in pituitary and hypothalamus that functions in growth hormone release. Science, 273: 974-977.

Kojima, M., H. Hosoda, Y. Date, M. Nakazato, H. Matsuo and K. Kangawa, 1999. Ghrelin is a growth-hormone-releasing acylated peptide from stomach. Nature, 402: 656-660.

Korbonits, M., S.A. Bustin, M. Kojima, S. Jordan, E.F. Adams and D.G. Lowe, 2001. The expression of the growth hormone secretagogue receptor ligand ghrelin in normal and abnormal human pituitary and other neuroendocrine tumors. J. Clin. Endocrinol. Metab., 86: 881-887.

Kyewski, B., J. Derbinski, J. Gotter and L. Klein, 2002. Promiscuous gene expression and central T-cell tolerance: More than meets the eye. Trends Immunol., 23: 364-371.

Ritter, M.A. and D.B. Palmer, 1999. The human thymic microenvironment: New approaches to functional analysis. Semin Immunol., 11: 13-21.

Rouse, R.V., L.M. Bolin, J.R. Bender and B.A. Kyewski, 1988. Monoclonal antibodies reactive with subsets of mouse and human thymic epithelial cells. J. Histochem. Cytochem., 36: 1511-1517.

Smith, R.G., 2005. Development of growth hor- mone secretagogue. Endocr. Rev., 26: 346-360. 